\title{
Why do people leave marked trails? Implications for managing outdoor recreationists
}

\author{
Vera Kopp \& Joy Coppes
}

Keywords: outdoor recreation, wildlife, visitor behaviour, off-trail, visitor management

\section{Abstract}

Outdoor winter sports activities are growing in popularity, causing conflicts with sensitive wildlife species. Many studies have shown negative effects of recreational activities on wildlife, with off-trail activities considered to be more detrimental compared to activities performed on marked trails. Small hand-held global positioning devices are readily available, facilitating navigation off marked trails. For adequate visitor management, it is essential to know the motives of visitors to nature areas. The motives of recreationists to leave marked trails are, however, rarely known. Using questionnaires, we studied why people leave trails and analysed the predictors according to the Fietkau-Kessel grid model of environmental behaviour. The main motives for leaving a marked trail were more fun compared to staying on marked trails, previous experience of guided tours which left marked trails, and the signs being unclear. High-quality recreation infrastructure significantly reduces the chances of leaving marked trails, and a person with a positive attitude towards wildlife conservation is more likely to stay on the trails. We recommend visitor-steering management that combines attractive recreation infrastructure and clear signposts with methods influencing people's attitudes towards nature conservation and education to foster on-trail activities.
Profile

Protected area

Schavinsland and

Feldberg

Mountain range

Black Forest

Country

Germany

\section{Introduction}

Nature-based recreation and outdoor activities are increasing worldwide (Eagles et al. 2002; Hennig et al. 2011). Technological advances (e.g. e-bikes, pedelecs, GPS) allow new areas to be used for recreation and activities to be performed during the day or night (e.g. high-powered LED head lamps). Consequently, spatial and temporal recreational use of the landscape has intensified (Hennig et al. 2011). Nature-based recreational activities can, however, conflict with another function of forests - the preservation of natural habitats and biodiversity (Green et al. 2004; Niemelä et al. 2005; Pröbstl et al. 2010) - with recreation even being recognized as a threat for a wide range of species (Ballantyne et al. 2013; BirdLife International 2015). Freeliving animals (from now on referred to as wildlife) react in a similar fashion to the presence of humans as to predators (Frid et al. 2002). Human recreationists can affect the behaviour, physiology, survival rate, reproduction rate and population dynamics of wildlife (Larson et al. 2016; Tablado et al. 2015). Off-trail activities (e.g. snowshoeing and ski touring) are a non-predictable threat for wildlife, limiting their possibilities to adapt to human disturbances (Geist 1978; Miller et al. 2001). Wildlife shows greater flushing distances (Baines et al. 2007; Miller et al. 2001) or greater vigilance distances (Taylor et al. 2003) when humans carry out activities away from marked recreational trails compared to on-trail activities. Consequently, to reduce the negative effects of recreation activities, visitor-steering measures should aim at keeping people on the marked trails. Although previous studies show what environmental factors affect where people leave marked trails (Coppes et al. 2013), the factors affecting why people leave the trails remain unknown. For adequate visitor management, more knowledge of the factors influencing people to leave trails is needed, which can in turn be applied to change visitor behaviour.

In studies focusing on changing behaviour, some of the most commonly discussed influencing factors are: people's attitudes towards a specific topic (Hines et al. 1986); knowledge (of a problem's content and of solution options) (Kaiser et al. 2003); the possibility to act pro-environmentally (Homburg et al. 1998), and perceived consequences, which means that if people are capable of reflecting on the consequences of their behaviour they are more willing to adjust their behaviour (Kollmuss et al. 2002). These factors are known to influence behaviour in general but have not yet been tested regarding their influence on offtrail behaviour in a wildlife context. We developed a conceptual model and used questionnaires to study (1) people's motives to leave trails, and (2) the factors that influence people's off-trail behaviour. Our results provide a basis for appropriately designed visitor management concepts that facilitate the coexistence of wildlife and recreationists in highly-frequented winter sports regions in Central Europe. 

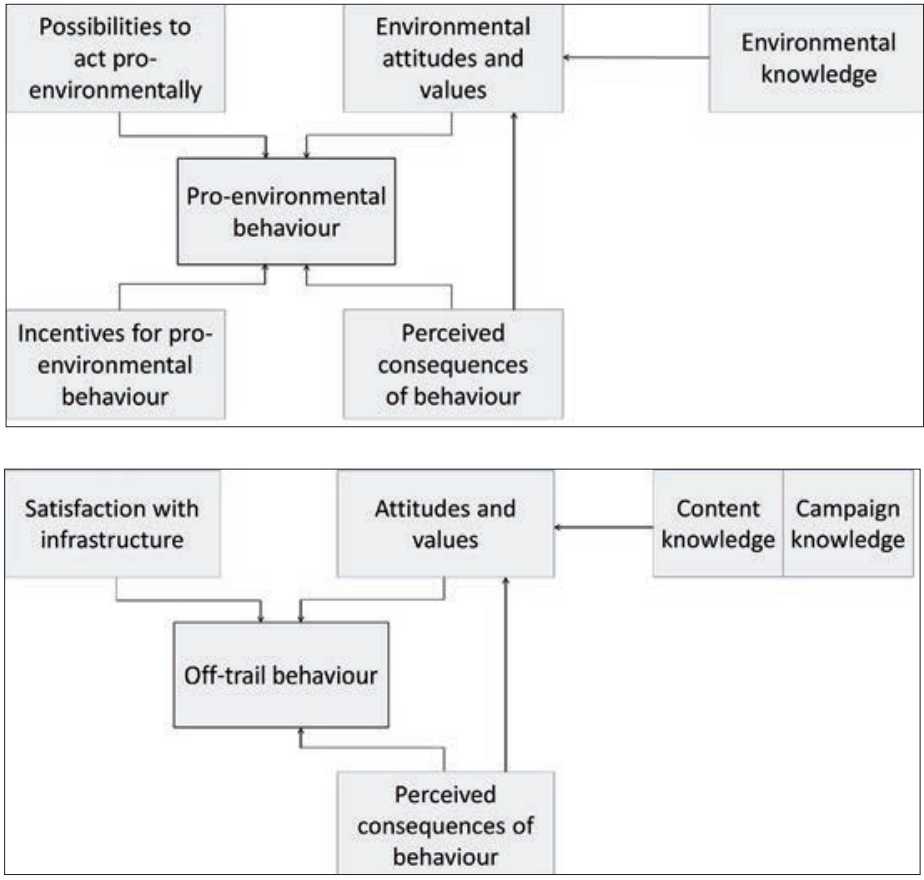

Figure 1 - Model of ecological behaviour by Fietkan et al. 1981 (Kollmuss et al. 2002).

Figure 2 - The conceptual model explaining offtrail behaviour, with the relevant predictors.

\section{Materials and methods}

\section{Conceptual model and operationalization}

In order to identify influencing predictors for offtrail behaviour, we developed a conceptual model based on the model of ecological behaviour by Fietkau et al. (1981) (Figure 1). This model explains environmental behaviour as being dependent on five predictors.

We modified the Fietkau-Kessel grid model with predictors that are applicable for off-trail behaviour (Figure 2 and Table 1). According to the original model of Fietkau et al. (1981), it is assumed that knowledge about wildlife-related topics correlates positively with attitudes towards wildlife and values placed on it, and thus reduces off-trail behaviour. The predictor knowledge was divided into campaign knowledge (i. e. knowledge of a campaign addressing the topic of off-trail behav- iour) and content knowledge (i.e. knowledge of the effects of off-trail behaviour on wildlife) to test whether there was a difference between the types of knowledge that are conveyed. According to Fietkau's original model, the predictor attitudes and values is assumed to be positively influenced by the predictor perceived consequences of behaviour. This means that people who know about the consequences of their behaviour for wildlife have positive attitudes and values and are less likely to go off-trail. It is further assumed that the predictor satisfaction with infrastructure will reduce off-trail behaviour. The predictor incentives to act pro-environmentally was excluded as there were no penalties for off-trail behaviour enforced in the study area during the study period, and no rewards for staying on the trails.

For the analysis of the explanatory predictors, two predictors were constructed in the context of knowl-

Table 1 -Description of the predictors tested in the model for influence on off-trail behaviour and sample questions for each from the questionnaire.

\begin{tabular}{|l|l|l|}
\hline Predictors & Description & Sample item for the questionnaire \\
\hline $\begin{array}{l}\text { Campaign } \\
\text { knowledge }\end{array}$ & $\begin{array}{l}\text { assumes that people with knowledge about local campaigns } \\
\text { and initiatives regarding behavioural rules will stay on-trail }\end{array}$ & $\begin{array}{l}\text { "Have you ever heard any the following terms?" Options: } \\
\text { wildlife protection zone, stay on-trail, capercaillie action } \\
\text { plan, campaign bewusstWild' }\end{array}$ \\
\hline $\begin{array}{l}\text { Content } \\
\text { knowledge }\end{array}$ & $\begin{array}{l}\text { assumes that people with knowledge of the consequences of } \\
\text { human disturbances will stay on-trail }\end{array}$ & $\begin{array}{l}\text { "Do you know to what type of disturbance wildlife can adapt } \\
\text { better?" Options: regular disturbances, frequent disturbanc- } \\
\text { es, irregular disturbances, rare disturbances }\end{array}$ \\
\hline $\begin{array}{l}\text { Satisfaction } \\
\text { with } \\
\text { infrastructure }\end{array}$ & $\begin{array}{l}\text { assumes that people who are satisfied with the infrastructure } \\
\text { provided will stay on-trail }\end{array}$ & $\begin{array}{l}\text { "Please indicate how satisfied you are with the trail offer" } \\
\text { Options: very satisfied, satisfied, partly satisfied, not very } \\
\text { satisfied, not satisfied at all, I don't know }\end{array}$ \\
\hline $\begin{array}{l}\text { Attitude and } \\
\text { values }\end{array}$ & $\begin{array}{l}\text { assumes that people with positive attitudes and values with } \\
\text { respect to wildlife will stay on-trail }\end{array}$ & $\begin{array}{l}\text { "If my favourite route is closed due to wildlife protection } \\
\text { measures, I would be annoyed" Options: I totally agree, I } \\
\text { agree, I partly agree, I don't agree at all, I don't know }\end{array}$ \\
\hline $\begin{array}{l}\text { Perceived } \\
\text { consequences } \\
\text { of behaviour }\end{array}$ & $\begin{array}{l}\text { assumes that people who know about the possible conse- } \\
\text { quences of their behaviour for wildlife will stay on-trail }\end{array}$ & $\begin{array}{l}\text { "Wildlife is used to winter sports activities and thus does not } \\
\text { feel threatened" Options: I totally agree, I agree, I partly } \\
\text { agree, I don't agree at all, I don't know }\end{array}$ \\
\hline
\end{tabular}

${ }^{1}$ bewusstWild is a campaign that offers information on how to behave in wildlife-friendly manner (e.g. to stay on-trail) during outdoor activities (www.bewusstwild.de). 


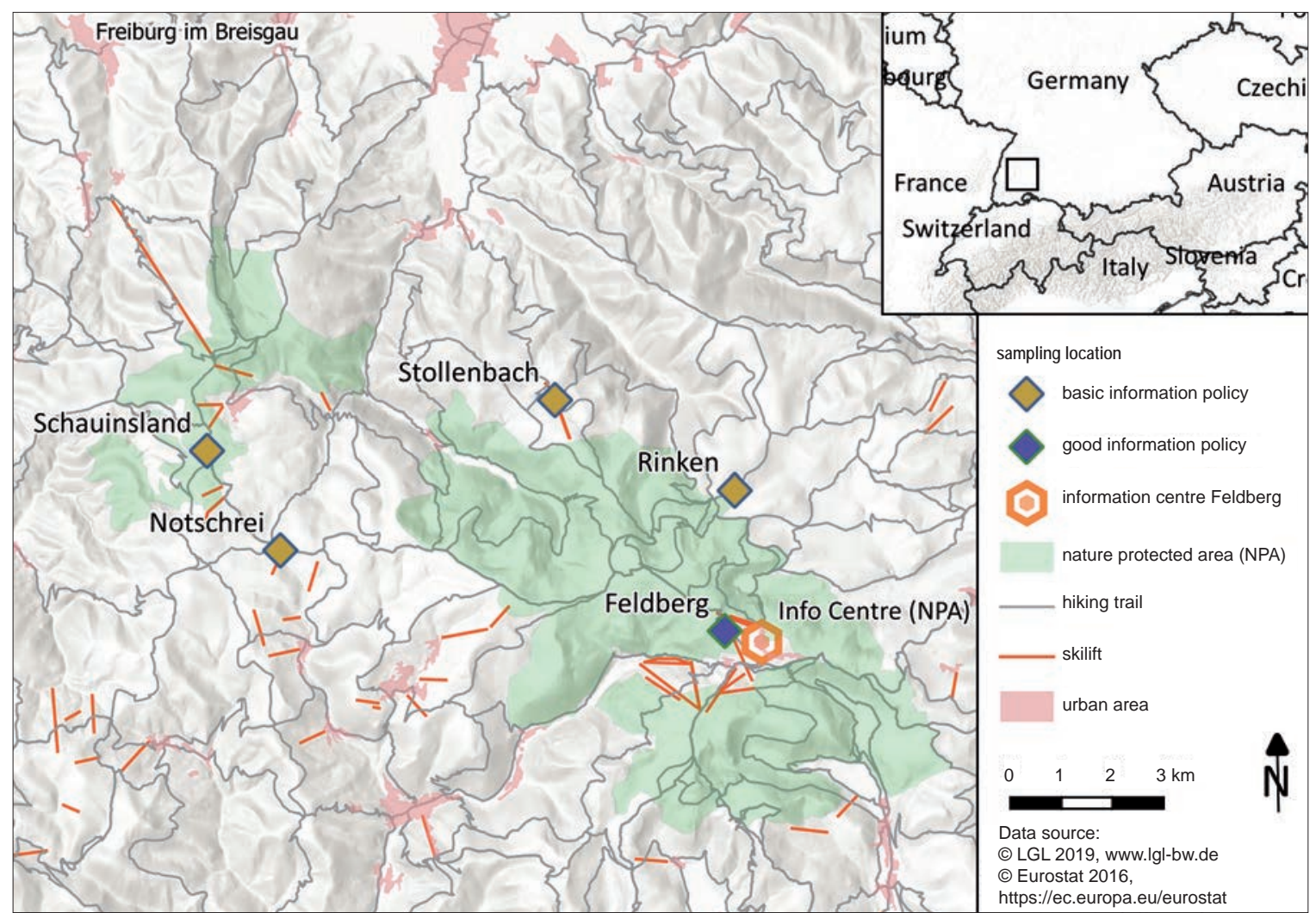

Figure 3 - Study area showing the two PAs Schauinsland and Feldberg and the five questionnaire sites according to their information policies basic and good.

edge. Content knowledge was created by calculating the sum score of the appropriate answers of the knowledge item. The predictor campaign knowledge was calculated as the sum of the knowledge items of initiatives and campaigns. The predictors satisfaction with infrastructure, attitude and values and perceived consequences of behaviour were also assessed. A confirmatory factor analysis showed that two predictors can be distinguished (Tucker-Lewis-Index (TLI) $=0.970$, Comparative Fit Index $(\mathrm{CFI})=0.976$, Root Mean Square Error of Approximation $(\mathrm{RMSEA})=0.059)$ : pro-wildlife attitudes and satisfaction with trails (Table 2). Cronbach's $\alpha$ for the reliability of the new predictors was determined as 0.703 and 0.966 respectively. These values indicate the correlation of a variable with a predictor. The positive values indicate that both factors correlate positively with the variables. Factor loading ' 0 ' means that factor and variable are stochastically independent; '1' means complete correlation. Both predictors combined explained almost $35 \%$ of the variance of all variables in the model.

The first predictor, pro-wildlife attitudes, consists of 7 items ranging from attitude and values items to perceived consequences of behaviour items. This means that the originally distinct predictors of the conceptual model attitude and values and perceived consequences of behaviour could not be considered separately but belong together. The second predictor, satisfaction with trail, implied all four original items which refer to being satisfied: comprehensibility, variety and number of trails,

Table 2 - Results of factor loadings for the items of the predictors pro-wildlife attitude and satisfaction with trails.

\begin{tabular}{|l|r|r|}
\hline Items & $\begin{array}{l}\text { Pro-wildlife } \\
\text { attitude }\end{array}$ & $\begin{array}{l}\text { Satisfaction } \\
\text { with trails }\end{array}$ \\
\hline Alternative routes & 0.962 \\
\hline Number of trails & 0.947 \\
\hline Variety of trails & 0.942 \\
\hline Clarity of trail signs & 0.920 \\
\hline I consider it important to create sufficient habitat for wildlife & 0.670 \\
\hline I consider it reasonable to close trails during winter in order to protect wildlife & 0.645 \\
\hline I feel uncomfortable at the thought that my winter sport activity might disturb wildlife & 0.619 \\
\hline The media should report more on the effects of winter sports on wildlife & 0.593 \\
\hline I consider it reasonable to designate wildlife protection areas in order to provide wildlife refuges & 0.576 \\
\hline I feel satisfied, knowing that my personal restrictions help survival of wildlife & 0.568 \\
\hline In forests, it is important to stay quiet calm in order not to disturb wildlife & 0.533 \\
\hline
\end{tabular}


and alternative routes. The predictor off-trail was calculated as the sum score of the items I have already been offtrail during one of my tours vs. I have never been off-trail during one of my tours and considered as a dependent variable.

\section{Study area}

The study area is located in the Southern Black Forest, a lower mountain range in South-Western Germany (Figure 3). The area is a destination for outdoor recreation all year around but is known especially for its various winter sports activities, such as backcountry skiing, snowshoeing and winter hiking, making it one of the most important generators of income for the region (Gebhardt 2016). Off-trail activities such as ski touring and snowshoeing have gained in popularity in recent years. At the same time, the area is home to a threatened subpopulation of capercaillie (Tetrao urogallus) (Coppes et al. 2019) and is close to the Southern Black Forest red deer (Cervus elaphus) management area (Suchant et al. 2008). Both species are highly susceptible to irregular disturbances by humans (Reimoser 2012; Thiel 2007) and known to adapt their behaviour according to human presence and recreational infrastructure (Coppes et al. 2017a; Coppes et al. 2017b). The occurrence of these species plays an important role in determining the approval or rejection of applications for licences for new recreational activities in the study area.

Local legislation generally allows leaving marked trails in the forests; only in the designated protected areas (PAs) Schauinsland and Feldberg is it prohibited to go off-trail. Although nature-protection legislation is the same for Feldberg and Schauinsland, the areas differ regarding their information policies. The PA Schaninsland is relatively small and people can easily cross the border into it when visiting non-protected areas. Here, the information policy gives basic information signs on-site, limited waymarking of trails, and no additional information on how winter sports are affecting wildlife. The Feldberg area has an extensive information policy: there is an information centre, and signs and rangers inform people on-site. Additionally, information regarding environment- and wildlife-friendly behaviour is provided, which can also be found on the information centre's website (www.naz-feldberg.de). Consequently, we divided our study area into sites with basic information policy (Schauinsland, Notschrei, Rinken, Stollenbach), and a site with good information policy (Feldberg) (Figure 3).

\section{Questionnaire and survey}

Based on a pre-tested questionnaire, a survey was designed according to the standards of Kirchhoff et al. (2010). In the winter of 2014, the questionnaires were handed personally to recreationists (winter hikers, snowshoe walkers and backcountry skiers) to be filled out when they returned from their tours to five different carparks and end-points of marked winterhiking and snowshoe trails. The survey took place during randomly selected days in January and February, with an emphasis on weekends when people were likely to be more relaxed and therefore more open to participate. The survey consisted of qualitative and quantitative questions which were based on a bipolar Likert scale ranging from 1 to 5 .

We asked people directly whether they had been offtrail either during their visit that day or ever before. We also asked for satisfaction with infrastructure, attitudes towards and values placed on wildlife, knowledge of wildlife-related topics, and whether people perceived the consequences of their behaviour, and used open questions to ask for people's motives in leaving trails.

\section{Statistical analysis}

Descriptive statistics were used to determine visitor characteristics (quantitative questions) and to describe visitor motivations (qualitative questions) for leaving marked trails. In order to identify the predictors which influence off-trail behaviour and describe the relationships between the predictors, we developed a predictive model. Here, the variable Off-trail was considered as a dichotomous variable ( $I$ had already been off-trail during one of my tours vs. I have never been off-trail during one of my tours). This was regarded as a dependent variable, and potential behaviour predictors were tested for their influence on off-trail behaviour. A two-step approach was chosen, consisting of factor analysis, and logistic and linear regression. Next, the correlations between the calculated predictors and the dependent variable were calculated using a regression model. Analyses were conducted using IBM SPSS Statistics 22. The significance level chosen was $\mathrm{p} \leq 0.05$.

\section{Results}

\section{Visitor Characteristics}

A total of 190 people who practised winter hiking, snowshoeing or ski touring participated in the survey (43\% females, 57\% males). Most practised snowshoeing $(60 \%)$, followed by winter hiking $(50 \%)$ and crosscountry skiing $(22 \%)$. Almost a third $(31 \%)$ practised either two or three of the activities. Most people lived in Baden-Württemberg (81\%); others were from other parts of Germany (11\%); the remainder were from neighbouring countries ( $8 \%$ ). The majority of the people questioned had planned their tour in advance $(60 \%)$, mainly based on recommendations by friends $(22 \%)$, the internet $(15 \%)$, or using maps $(7 \%)$. Others planned on site by means of flyers $(6 \%)$, information signs $(3 \%)$ and guide books $(3 \%)$, or by consulting local people $(3 \%)$. Those who had not planned their tour in advance gave their reasons as good local knowledge $(22 \%)$, participation in a guided tour $(9 \%)$, orientation using the on-site signage $(7 \%)$, or having no idea where to go for information $(2 \%)$. 

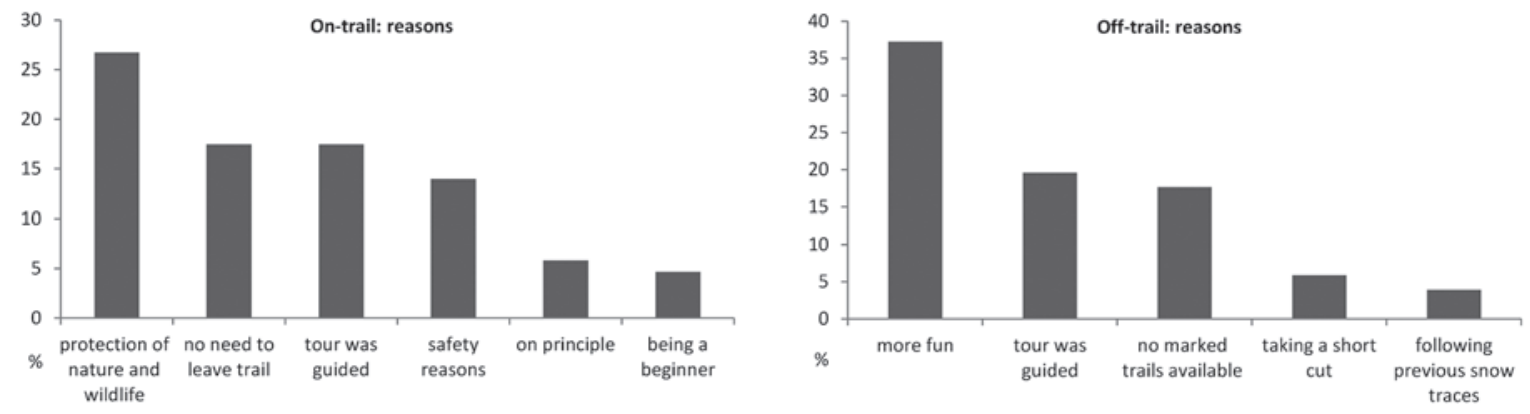

Figure 4 - Percentage of people giving reasons to stay on designated trails (left) and to go off-trail (right).

Motivation for leaving marked trails

The response rate regarding going off-trail was very high $(98 \%)$. Most recreationists declared that they had not left the trails during their visit (65\%). The main reasons given were protection of nature and wildlife (27\%), no need to leave trails (17\%), and participation in a guided tour $(17 \%)$ (Figure 4). More than a third of the people $(35 \%)$ stated that they had left their trail. The main raisons for going off-trail were that it was more fun (37\%), participation in a guided tour (20\%), and unclear signage $(18 \%)$ (Figure 4). Of those who went off-trail, $8 \%$ ventured into open landscapes, $10 \%$ made their way along forest edges, and $4 \%$ left the trails for a combination of forest edges, forest and open landscapes. $13 \%$ of respondents did not give information about where they left the trails.

\section{Off-trail behaviour: prediction model}

According to logistic regression analysis, satisfaction with infrastructure was a significant predictor for going off-trail. The more recreationists were dissatisfied with infrastructure, the more they decided to go off-trail $(p=0.013)$. If they were dissatisfied with the recreational trails available, the probability of leaving the designated trails increased by the predictor 1.24 (24\%). Second, campaign knowledge showed a significant negative correlation with going off-trail. The more campaign knowledge recreationists had, the less they decided to go off-trail $(\mathrm{p}=0.026)$. The linear regression predicting knowing about wildlife campaigns and content knowledge showed that the more recreationists thought and felt pro-wildlife, the more they knew about wildlife campaigns $(p=0.001)$, and consequently they stayed on-trail more often (Figure 5). The predictor content knowledge did not influence off-trail behaviour, either directly or indirectly (Figure 5).

Recreationists were more likely to go off-trail when information policy was only basic (63\% left trails), but were more likely to stay on-trail if a good information policy was in place $(49 \%$ left trails $)(p=0.047)$. The prediction models for both information policy areas were the same, except for the predictor satisfaction with trails: the predictor significantly $(p=0.031)$ affected off-trail behaviour when basic information policy was given, but not $(p=0.212)$ in the area with a good information policy.

\section{Discussion}

Exposing underlying motives and reasons as well as predictors for off-trail behaviour, this study is the first to show why winter recreationists leave marked trails. By applying the conceptual model and combining it with questionnaires, we reveal clear management options to reduce the off-trail behaviour of outdoor recreationists. So far, off-trail behaviour has been assessed either in a spatial context, i. e. where people leave trails (Coppes et al. 2013), or in the context of the reactions of wildlife to off-trail activities (Mainini et al. 1993; Miller et al. 2001; Taylor et al. 2003). These studies reveal the importance of visitor-steering and management to keep visitors on the marked trails. For

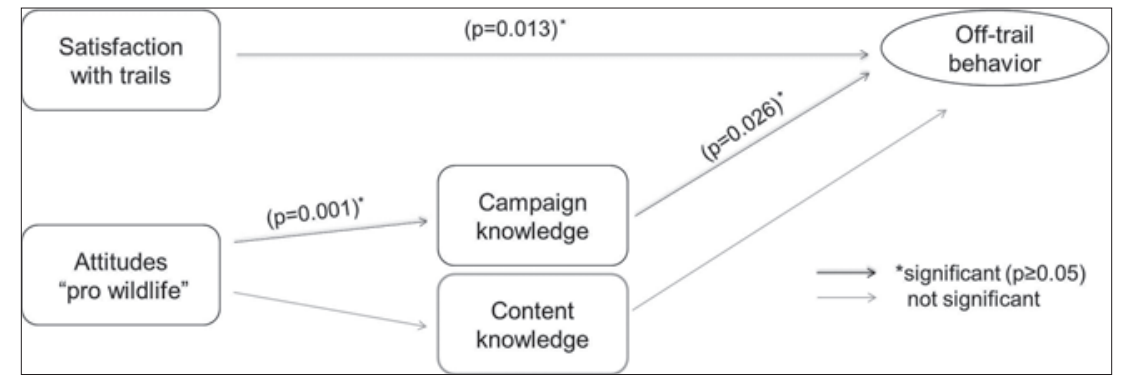

Figure 5 - Prediction model explaining off-trail behaviour of winter recreationists. The arrows indicate a significant correlation between the factors and off-trail behaviour. The pale dashed arrows indicate factors which did not affect off-trail behaviour signifcantly. The factors affecting off-trail behaviour significantly were satisfaction with infrastructure and pro-wildlife attitude via campaign knowledge. The factor content knowledge was not significant for off-trail behaviour. 
effective management, however, knowledge of how to influence visitor behaviour is crucial. Previous studies that assess predictors influencing recreationists' behaviour focus on responsible behaviour in general (e.g. Kil et al. 2014; Klöckner 2013; Kollmuss et al. 2002), the acceptance of steering measures (Arnberger et al. 2012; Immoos et al. 2015; Sterl et al. 2010; Zeidenitz et al. 2007), or the attitude of recreationists towards management measures (Sterl et al. 2010). However, these studies fail to test and address how to influence visitor behaviour using management measures. Although it has been suggested that public relations and communication measures can be effective to minimize conflicts between the needs of wildlife and those of recreationists (Graf et al. 2018), these proposals have not been substantiated by scientific results. Our results offer management options based on a scientific methodology.

Respondents said they left a trail to go into open landscape or move along forest edges, while a few went into the forest. This result is in line with Coppes \& Braunisch (2013), who showed that with an increase of canopy cover, the probability of people going off-trail decreases. An important motive for staying on-trail and for going off-trail was participation in a guided tour. Hence, we recommend that tour guides should be given further training in informing the public regarding wildlife-friendly behaviour during winter sports activities. Although we cannot show that the motivation for going off-trail is a predictor for leaving marked trails, our results indicate that the motivation to do so might differ from the typical recreation motivations. In their responses to the qualitative questions regarding off-trail behaviour, respondents did not name escape, recreation, nature experience or solitude (Arnberger et al. 2010), or fitness, adventure/thrill or saving costs (Zeidenitz et al. 2007) as motives for off-trail behaviour. We recommend future research to assess whether there are specific recreation motivations that trigger off-trail activities. Respondents also gave unclear signage as one of the main reasons they left trails. Here, local management should ensure that information is adequate and readily understandable, and implement a standardized information policy using consistent signs which are visible also during snowfall.

The results of the prediction model revealed that people who are satisfied with the infrastructure provided are less likely to go off-trail. This result is in line with the findings of other authors (Freuler et al. 2007; Kollmuss et al. 2002) who showed that appropriate infrastructure can positively steer people, as it helps visitors to put their positive attitudes into practice. As the trail offer is different between summer and winter in the study area, Coppes and Braunisch (2013) found that recreationists left trails in winter, to continue on (closed) summer infrastructure. This behaviour was more pronounced where summer-trail signs were present, indicating the significance of signage and infrastructure for visitor steering.
We found that recreationists are more likely to go off-trail when information policy is only basic. This result is supported by Freuler et al. (2007), who show that the level of information provided strongly influences behaviour. With regard to the prediction model, we were able to show that people who are dissatisfied with trails (model predictor: satisfaction with trails) are more likely to leave trails in the basic information policy area than in the good information policy area. This result confirms the findings of Immoos et al. (2015), who state that simple waymarking is not sufficient to steer visitor behaviour as required: good information already during the planning phase of a visit or at its starting point triggers people to behave in the hoped-for way.

Although attitudes towards wildlife and related steering measures were positive overall, respondents still left trails. As implementing visitor-steering efforts is shown to be compatible with attitudes (Freuler et al. 2007), there is a discrepancy between attitudes and behaviour. This phenomenon has been addressed by several authors (e.g. Freuler et al. 2007; Homburg et al. 1998; Kollmuss et al. 1998) who state that, although people are generally willing to behave in a manner that respects the environment and are emotional about this topic, in fact their behaviour shows little conformity with these attitudes. Nevertheless, attitudes are considered to play an important role in fostering pro-environment behaviour (Bamberg et al. 2007; Hines et al. 1986). This is in line with the present results, which indicate a strong relationship between (campaign) knowledge and attitudes.

Our results indicate that the predictive power of knowledge depends on the type of knowledge. The knowledge predictor was divided into content knowledge and campaign knowledge, in line with other authors (e.g. Kaiser et al. 2003). A pro-wildlife attitude was a significant predictor for campaign knowledge. Thus it can be concluded that if people already have the appropriate attitudes, as the respondents did, providing information via campaigns will have a positive effect on off-trail behaviour (Manning 2003; Marion et al. 2007; Zeidenitz et al. 2007). This supports the results of Freuler et al. (2007) that the gap between attitudes and behaviour can be reduced if recreationists are provided with appropriate information, good arguments and appeals for them to act responsibly. The positive effects of campaign knowledge on behaviour were also shown by Immoos et al. (2014). As demonstrated by earlier studies (Kollmuss et al. 2002), content knowledge is not significant in predicting off-trail behaviour. It can be deduced that procedural knowledge, which explains how to behave (transferred by campaigns), is more effective in changing behaviour than providing simple content knowledge.

\section{Conclusion}

We identified satisfaction with infrastructure as the strongest predictor for not leaving trails, especially 
in areas with basic information policies. The results further show that a positive attitude towards wildlife implies a better knowledge of wildlife campaigns and consequently encourages people to stay on-trail. Furthermore, we show that an extensive information policy can play an important role in visitor-steering in nature areas. Our findings suggest measures which could be included in visitor management in nature areas. Future studies should assess how to effectively communicate knowledge to the target groups. As our results indicate that most people planned their tour in advance, not relying simply on on-site information sources, the effectiveness of off-site communication measures (e.g. information in magazines, on websites or apps) should be tested. The role of subjective norms (the attitudes of the individual's social group, friends and relatives, or of tour guides) could also be studied to optimize communication measures. We show how the use of a qualitative social science approach can reveal new insights which are important for reducing human-wildlife conflicts.

\section{Acknowledgements}

We are grateful to all the respondents who agreed to participate in our study. We would also like to thank everyone supporting the data collection and are grateful to Prof. Dr. Janina Strohmer for help with the statistical analysis.

\section{Declaration of interests and funding details}

The authors declare that they have no competing interests. This work was supported by the Ministry of Rural Affairs and Consumer Protection Baden-Württemberg. The funding organization played no role in the study design, data collection, analysis or interpretation of the results.

\section{References}

Arnberger, A., R. Eder, B. Allex, P. Sterl \& R.C. Burns 2010. Exploring relationships between visitor motives, satisfaction, recreation quality and attitudes towards rotected area management in the Gesaeuse National Park, Austria. In: Gossen, M., B. Eilands \& R. van Marwijk (eds.), Recreation and tourism in a changing world: 63-64.

Arnberger, A., R. Eder, B. Allex, P. Sterl \& R.C. Burns 2012. Relationships between national-park affinity and attitudes towards protected area management of visitors to the Gesaeuse National Park, Austria. Forest Policy and Economics 19: 48-55.

Baines, D. \& M. Richardson 2007. An experimental assessment of the potential effects of human disturbance on Black Grouse Tetrao tetrix in the North Pennines, England. Ibis 149: 56-64.

Ballantyne, M. \& C.M. Pickering 2013. Tourism and recreation: a common threat to IUCN red-listed vas- cular plants in Europe. Biodiversity and Conservation 22: 3027-3044.

Bamberg, S. \& G. Möser 2007. Twenty years after Hines, Hungerford, and Tomera: A new meta-analysis of psycho-social determinants of pro-environmental behaviour. Journal of Environmental Psychology 27: 14-25.

BirdLife International 2015. European red list of birds. Luxembourg: Office for official publications of the European communities. doi: 10.2779/975810

Coppes, J. \& V. Braunisch 2013. Managing visitors in nature areas: where do they leave the trails? A spatial model. Wildlife Biology 19: 1-11.

Coppes, J., F. Burghardt, R. Hagen, R. Suchant \& V. Braunisch 2017a. Human recreation as a determinant of temporal habitat use patterns in red deer (Cervus elaphus). PLoS One 12.

Coppes, J., J. Ehrlacher, G. Müller, K. Roth, K. Schroth, M. Förschler, V. Braunisch \& R. Suchant 2019. Dramatic decline of the Capercaillie Tetrao urogallus population in the Black Forest. Vogelwarte 57: 115-122.

Coppes, J., J. Ehrlacher, D. Thiel, R. Suchant \& V. Braunisch 2017b. Outdoor recreation causes effective habitat reduction in capercaillie Tetrao urogallus: a major threat for geographically restricted populations. Journal of Avian Biology 48(12): 1583-1594.

Eagles, P.F.J., S.F. McCool \& C.D.A. Haynes 2002. Sustainable Tourism in Protected Areas: Guidelines for Planning and Management. IUCN Gland, Switzerland and Cambridge, UK.

Fietkau, H.-J. \& H. Kessel 1981. Umweltlernen. Königstein/Ts. [In German]

Freuler, B. \& M. Hunziker 2007. Recreation activities in protected areas: bridging the gap between the attitudes and behaviour of snowshoe walkers. Forest Snow and Landscape Research 81: 191-206.

Frid, A. \& L. Dill 2002. Human-caused Disturbance Stimuli as a Form of Predation Risk. Conservation Ecology 6(1): 11. Available at: http://www.consecol.org/ vol6/iss1/art11 (accessed 06/03/2020)

Gebhardt, H. 2016. Fremdenverkehrsgebiete. Landeszentrale für politische Bildung: Landeskunde BadenWürttemberg. Available at: http://www.landeskundebaden-wuerttemberg.de/3383.html [In German]

Geist, V. 1978. Behaviour. In: Schmidt, J.L. \& D.L. Gilbert (eds.), Big game of North America: ecology and management: 283-296.

Graf, R.F., C. Signer, M. Reifler-Bächtiger, M. Wyttenbach, B. Sigrist \& R. Rupf 2018. Wildtier und Mensch im Naherholungsraum. Swiss Academies Factsheets 13(2). Available at: https://naturwissenschaften.ch/uuid/684b6e6c-f28d-55c6-b786-6cc4e0 ec4adb?r=20190807115818_1565139634_e48acf1acf10-560c-b13a-a67081dadef9 (access 06/03/2020) [In German]

Green, R. \& M. Giese 2004. Negative effects of wildlife tourism on wildlife. In: Higginbottom, K. (ed.), Wildlife tourism: impacts, management and planning: 81-98 
Hennig, S. \& M. Künzl 2011. Applying Integrated Nature Conservation Management: Visitor Management and Monitoring of Winter Recreation Activities Focusing Grouse Species in Berchtesgaden National Park. In: Zhelezov, G. (ed.), Sustainable Development in Mountain Regions: 239-253.

Hines, J.M., H.R. Hungerford \& A.N. Tomera 1986. Analysis and Synthesis of Research and Responsible Environmental Behaviour: A Meta-Analysis. The Journal of Environmental Education 18: 1-8.

Homburg, A. \& E. Matthies 1998. Umweltpsychologie. Weinheim/München. [In German]

Immoos, U. \& M. Hunziker 2014. Wirkung von Lenkungsmaßnahmen auf das Verhalten von Freizeitaktiven. Naturschutz und Landschaftsplanung 46: 5-9. [In German]

Immoos, U. \& M. Hunziker 2015. The effect of communicative and on-site measures on the behaviour of winter sports participants within protected mountain areas - results of a field experiment. eco.mont Journal on protected mountain areas research and management 7(1): 17-25.

Kaiser, F.G. \& U. Fuhrer 2003. Ecological Behavior's Dependency on Different Forms of Knowledge. Applied Psychology: An International Review 52: 598-613.

Kil, N., S.M. Holland \& T.V. Stein 2014. Structural relationships between environmental attitudes, recreation motivations, and environmentally responsible behaviors. Journal of Outdoor Recreation and Tourism 7-8: 16-25.

Kirchhoff, S., S. Kuhnt, P. Lipp \& S. Schlawin 2010. Der Fragebogen Datenbasis, Konstruktion und Auswertung. Wiesbaden. [In German]

Klöckner, C.A. 2013. A comprehensive model of the psychology of environmental behaviour - A metaanalysis. Global Environmental Change 23: 1028-1038.

Kollmuss, A. \& J. Agyeman 2002. Mind the Gap: Why do people act environmentally and what are the barriers to pro-environmental behavior? Environmental Education Research 8: 239-260.

Larson, C.L., S.E. Reed, A.M. Merenlender \& K.R. Crooks 2016. Effects of Recreation on Animals Revealed as Widespread through a Global Systematic Review. PLOS ONE 11: e0167259.

Mainini, B., P. Neuhaus \& P. Ingold 1993. Behaviour of marmots Marmota marmota under the influence of different hiking activities. Biological Conservation 64: 161-164.

Manning, R.E. 2003. Emerging Principles for Using Information/Education in Wilderness Management. International Journal of Wilderness 9: 20-28.

Marion, J.L. \& S.E. Reid 2007. Minimising Visitor Impacts to Protected Areas: The Efficacy of Low Impact Education Programmes. Journal of Sustainable Tourism 15: 5-27.

Miller, C.K., S.G. Miller \& R.L. Knight 2001. Wildlife Responses to Pedestrians and Dogs. Wildlife Society Bulletin 29: 124-132.
Niemelä, J., J. Young, D. Alard, M. Askasibar, K. Henle, R. Johnson, M. Kurttila, T.-B. Larsson, S. Matouch, P. Nowicki, R. Paiva, L. Portoghesi, R. Smulders, A. Stevenson, U. Tartes \& A. Watt 2005. Identifying, managing and monitoring conflicts between forest biodiversity conservation and other human interests in Europe. Forest Policy and Economics 7: 877-890.

Pröbstl, U., V. Wirth, B. Elands \& S. Bell 2010. Management of recreation and nature based tourism in European forests. Berlin.

Reimoser, S. 2012. Influence of Anthropogenic Disturbances on Activity, Behavior and Heart Rate of Roe Deer (Capreolus capreolus) and Red Deer (Cervus elaphus), in context of their daily and Yearly Patterns. In: Cahler A.A. \& J.P. Marsten (eds.), Deer: Habitat, Behaviour and Conservation: 1-96.

Sterl, P., R. Eder \& A. Arnberger 2010. Exploring factors influencing the attitude of ski tourers towards the ski touring management measures of the Gesäuse National Park. eco.mont - Journal on protected mountain areas research and management 2(1): 31-38.

Suchant, R. \& K.L. Gerecke 2008. Rotwild im Südschwarzwald: Konzeption eines integrativen Rotwild-Managements. Projektgruppe Rotwild. Freiburg, Germany. [In German]

Tablado, Z. \& L. Jenni 2015. Determinants of uncertainty in wildlife responses to human disturbance. Biological Reviews. Cambridge Philosophical Society 92: 216233. doi: $10.1111 /$ brv.12224

Taylor, A.R. \& R.L. Knight 2003. Wildlife Responses to Recreation and Associated Visitor Perceptions. Ecological Applications 13: 951-963.

Thiel, D. 2007. Behavioral and Physiological Effects in Capercaillie (Tetrao urogallus) Caused by Human Disturbance. Ph.D. Thesis, University of Zurich.

Zeidenitz, C., H.J. Mosler \& M. Hunziker 2007. Outdoor recreation: from analysing motivations to furthering ecologically responsible behaviour. Forest Snow and Landscape Research 81: 175-190.

\section{Authors}

\section{Vera Kopp}

works as a research assistant in the Wildlife and Disturbances research group, which studies the impact of human activities on wildlife. She is currently coordinating a project on human activities in wildlife habitats. Wildlife and Disturbance, Department of Wildlife Ecology, Forest Research Institute of Baden-Württemberg, Germany. E-mail: vera.kopp@fforst.bwl.de

Joy Coppes

leads the Forest Bird Research Group, which monitors and studies forest birds. The main research subjects of recent years have been the effects of climate change, anthropogenic disturbance and wind turbines on capercaillie. Forest Birds, Department of Wildlife Ecology, Forest Research Institute of Baden-Württemberg, Germany. 